\title{
Superstición y Weird Fiction: elementos conformadores en El amor no tiene cura, de Bernardo Esquinca.
}

\section{Superstition and Weird Fiction: conformation elements at El amor no tiene cura, by Bernardo Esquinca.}

\author{
Héctor Felipe Ramírez Núñez* \\ Facultad de Filosofía y Letras / Universidad Autónoma de Chihuahua (MÉXICO) \\ CE: $\underline{\text { ramfe.92@gmail.com ID ORCID: 0000-0002-9780-9302 }}$ \\ Iram Isaí Evangelista Ávila** \\ Facultad de Filosofía y Letras / Universidad Autónoma de Chihuahua (MÉXICO) \\ CE: ievangelista@uach.mx ID ORCID: 0000-0002-1065-082X
}

DOI: $10.32870 /$ sincronia.axxiii.n76.20b19

Esta obra está bajo una Licencia Creative Commons Atribución-NoComercial 4.0 Internacional

\begin{abstract}
* Licenciado en Letras Españolas por la Facultad de Filosofía y Letras de la Universidad Autónoma de Chihuahua y pasante del Máster en Humanidades en la División de Estudios de Posgrado de la misma institución. Actualmente es becario del Fondo Nacional para la Cultura y las Artes (FONCA) en la disciplina de Letras con especialidad en Novela. Correo electrónico: RamFe.92@gmail.com
\end{abstract}

\footnotetext{
** Doctor en Humanidades-Literatura por parte de la UAM-I. Docente en la Licenciatura en Letras Españolas, Maestría en Investigación Humanística y Doctorado en Educación, Artes y Humanidades (PNPC) en la UACH. Miembro del Sistema Nacional de Investigadores, nivel I. Contacto como autor por correspondencia email: ievangelista@uach.mx
}

Recibido: 05/03/2019

Revisado: 04/04/2019

Aprobado: 09/05/2019 


\title{
RESUMEN
}

La superstición es un elemento cultural que permea en el ejercicio de la literatura fantástica mexicana. A la vez, Weird Fiction, o ficción de lo extraño, cobra una relevancia capital para el soporte de la acción narrativa. En la obra de Bernardo Esquinca, el quebranto de las leyes naturales del mundo se da por el suceso supernatural que es detonado por un elemento supersticioso. Es por ello que la superstición llega a soportar la unidad total del cuento. Del mismo modo, las características propias de Weird Fiction nutren el corpus textual, por lo que surge una relación interdependiente entre ambos elementos, misma que garantiza el efecto de la narración y la hace sostenible.

Palabras clave: Sobrenatural. Carga simbólica. Narrativa. Atmósfera. Superstición.

\begin{abstract}
:
Superstition is a cultural element that permeates through the exercise of Mexican fantasy literature. At the same time, Weird Fiction acquires a main relevance to support the narrative action. In the work of Bernardo Esquinca, the rupture of natural laws is caused by the supernatural event detonated by superstition. For this reason, superstition carries the whole unit of the short-tale. In the same way, the characteristics of Weird Fiction feed the textual corpus giving rise to an interdependent relationship between both elements, which guarantees the narrative effects and makes it sustainable.
\end{abstract}

Keywords: Supernatural. Symbolic charge. Narrative. Atmosphere. Superstition.

\section{Superstición.}

La superstición suele entenderse como un estado mental similar a la sugestión, pero más allá de sus aspectos ideológicos o psicológicos, puede abordarse desde un punto de vista conductual. Susana Arroyo (2006) sostiene que la superstición comprende todos los comportamientos que contrarían a la religión oficial o al pensamiento puramente racionalista, pero que poseen un poderoso arraigo en la sociedad. De igual modo recalca la importancia de definir las diferencias fundamentales que existen entre los conceptos de magia y religión, donde la primera alude a una serie de ritos secretos 
que buscan el beneficio individual mediante la ayuda de la naturaleza y los seres sobrenaturales, y la segunda se aproxima a un fenómeno público, institucional y proselitista donde existen comportamientos grupales para alabar a una divinidad (pp. 3-4).

La superstición y la magia, poseen una relación estrecha, según Iñaki Bazán:

La magia aludiría a un pacto realizado con potencias sobrenaturales, con objeto de satisfacer los deseos y pasiones de los hombres, y cuando por su intercesión se logran cosas extraordinarias, pero debidas a causas naturales, se denomina magia blanca y cuando se consiguen mediante el concurso del diablo, negra o hechicería (1998, p. 107).

Bazán plantea a la superstición popular como un factor determinante para el surgimiento de la brujería, donde también intervienen los prejuicios basados en la ignorancia (según el cristianismo), así como el miedo colectivo insertado por la hegemonía cultural. Las "evidencias" hagiográficas son una pequeña muestra de los alcances del pensamiento supersticioso en los contextos litúrgicos. Para adentrarnos en el análisis nos apoyaremos en el concepto de hierofanía, que Mircea Eliade utiliza en Lo sagrado y lo profano (2012):

El hombre entra en conocimiento de lo sagrado porque se manifiesta, porque se muestra como algo diferente por completo de lo profano. Para denominar el acto de esa manifestación de lo sagrado hemos propuesto el término de hierofanía (del griego hieros = sagrado y phainomai = manifestarse), que es cómodo, puesto que no implica ninguna precisión suplementaria: no expresa más que lo que está implícito en su contenido etimológico, es decir, que algo sagrado se nos muestra (pp. 14-15).

El acto hierofante otorga una carga simbólica a un objeto o situación común y lo adopta como símbolo tangible. A saber: la cruz de cristo es el símbolo máximo del sacrificio y la devoción cristiana, adoptado a través de los pasajes bíblicos. De pronto, todo objeto que se asemeje a una cruz se convierte en depositario de simbolismo religioso. Sucede lo mismo con las imágenes de la Virgen María que aparecen en paredes, fotografías e incluso alimentos o en las tribus que toman a cierto animal como figura totémica. En palabras de Eliade, "no se trata de la veneración de una 
piedra o de un árbol por sí mismos. La piedra sagrada, el árbol sagrado no son adorados en cuanto tales; lo son precisamente por el hecho de ser hierofanías, por el hecho de 'mostrar' algo que ya no es ni piedra ni árbol, sino lo sagrado" (p. 15). El acto u objeto al que se le atribuyen tintes milagrosos se posiciona como un ejemplo de hierofanía. Asimismo, el horóscopo y/o el tarot que, ateniéndose a elementos universales, acierta una predicción, confirma el poder del ocultismo. Así, podemos inferir que las cargas simbólicas que se depositan en una cruz de madera, un pentagrama, un gato negro, la luna llena o un viernes trece se configuran a partir de hierofanías.

Enrique Enríquez, por su parte, desarrolla el concepto de superstición adhiriéndose a los efectos de la ficción en el hombre. En "Las supersticiones como modelo para entender el poder de la ficción" (2010) menciona lo siguiente:

Las supersticiones son pequeñas unidades narrativas modeladas tras una idea sencilla: imita lo que deseas, no imites lo que temes. De este modo nos invitan a ensayar metafóricamente lo que queremos atraer a nuestra realidad y nos prohíben actuar, incluso vía metáforas, lo que no quisiésemos experimentar a nivel literal. La superstición como pivote entre el miedo y la esperanza ofrece modelos del mundo que podemos controlar aunque no podamos controlar al mundo (p. 20).

La superstición provoca una reacción en el individuo, al grado de volverla parte de su imaginario y su estructura mental, la adecua a su quehacer cotidiano y le dota de un sentido propio que sirve para resanar las eventualidades propias de la vida.

Aunque la superstición se enfoca en los beneficios dirigidos a la individualidad, no deja de tener una faceta colectiva. Miguel Roiz (2002), en su artículo "Nuevas supersticiones de masa, medios de comunicación e ideología del conformismo" define a la superstición como:

Una tendencia colectiva a atribuir un carácter sobrenatural, sagrado y oculto, a determinados hechos relacionados con la naturaleza de la Tierra (como el Sol, la Luna o las estrellas) o bien procedentes de la acción humana (como la capacidad de hacer daño a otros o "mal de ojo") (p. 37). 
Y más allá de la acción humana, la superstición apela a cuestiones universales del ser humano, de modo que el interés supera el nivel social del individuo. Un ejemplo de ello es el horóscopo, que visto desde una óptica sociológica, puede considerarse como una superstición para las masas debido a que su destino, aunque individual, tiene alcances totalmente colectivos gracias al espacio que los medios de comunicación le han otorgado. De este modo puede difundirse sin tomar en cuenta las clases sociales y las áreas territoriales (p. 39).

\section{Weird Fiction.}

Según José Antonio Pulido (2004), los hombres primitivos se indujeron terror a sí mismos al aproximarse a lo descomunal, a lo no conocido, y al no encontrar explicaciones lógicas para dichos fenómenos (pp. 231-232). La importancia de estos elementos ancestrales es vital para rastrear los orígenes de los relatos Weird Fiction. Para Lovecraft (2014), el miedo es una de las emociones más poderosas y antiguas de la humanidad, y el miedo más antiguo y poderoso es el miedo a lo desconocido. El arraigo de esta emoción en el ser humano es inherente, y se motiva por instinto de supervivencia. Sin embargo, en la tradición literaria, es necesario que el lector posea un grado mínimo de imaginación para que el horror plasmado en el texto surta efecto (párr. 1, 2).

El autor norteamericano sostiene de igual manera que dentro del artificio de estas narraciones es imperativo el buen manejo de la atmósfera. El cuento Weird como toda tradición oral, busca un efecto en el receptor. Para Lovecraft (2014), la intención del emisor no lo es todo al momento de narrar. Se necesita prestar atención a las emociones que el cuento despierta en el receptor mediante sus elementos sobrenaturales. Estos cuentos van más allá de meras cuestiones tradicionales o visuales, dígase una osamenta ensangrentada o el sonido de las cadenas que arrastra un alma en pena:

A certain atmosphere of breathless and unexplainable dread of outer, unknown forces must be present; and there must be a hint, expressed with a seriousness and portentousness becoming its subject, of that most terrible conception of the human brain - a malign and particular suspension or defeat of those fixed laws of Nature which are our only safeguard 
against the assaults of chaos and the dæmons of unplumbed space [Debe respirarse una atmósfera de ansiedad e inexplicable temor ante lo ignoto, deben presentarse fuerzas desconocidas; y debe haber una pista, expresada con seriedad, de la más terrible concepción de la mente humana - la maligna y particular sensación de derrota de las leyes inmutables de la naturaleza, que son nuestro único refugio contra el asalto del caos y los demonios de los abismos exteriores (traducción propia)] (párr. 6).

Se trata de una especie de catarsis suscitada en el lector o receptor de la obra. Si el cuento Weird logra evocar las sensaciones pertinentes, entonces será considerado como tal, dejando de lado los medios de los que se valga para lograr sus efectos: "the one test of the really weird is simply this whether of not there be excited in the reader a profound sense of dread, and of contact with unknown spheres and powers" [La única prueba de lo verdaderamente Weird es esta: saber si el en el lector se excita un profundo sentimiento de pavor y si entra en contacto con esferas y poderes desconocidos (traducción propia)] (párr. 7).

De acuerdo con la crítica ejercida por Saijamari Männikkö (2002, p.10), en su disertación $H$. P. Lovecraft and the creation of horror, la construcción de personajes cobra relevancia en la constitución de Weird: "If humans were heroes in Lovecraft's world, he would not be a cosmic writer, and his tales would cease to be weird and horrifying" [Si los humanos fueran héroes en el mundo de Lovecraft, él no sería un escritor de lo cósmico, y sus relatos dejarían de ser Weird y horripilantes (traducción propia)], esto debido al patetismo con el que reviste a sus protagonistas, que, imposibilitados del entendimiento de los horrores cósmicos, se ven envueltos en la penumbra de la incertidumbre. Männikkö concluye: "one answer to the question how Lovecraft manages to create such disturbing horror is his philosophical conception of humanity's total insignificance" [Una respuesta a la pregunta de cómo Lovecraft logra crear un horror tan perturbador es su concepción filosófica de la total insignificancia humana (traducción propia)] (p. 61), confirmando el patetismo que caracteriza a los personajes del autor norteamericano. 
Otro aspecto interesante estriba en palabras de Kézia L'engle (2003), mismas que empatan con las ideas de Männikkö: "the elements that stand out from the average horror story are his particular blend of horror and science fiction, unique cosmic vision that emphasizes the cosmos, rather than man, and his careful crafting of atmosphere as virtually a main character" [Los elementos que destacan de la historia de horror promedio son su particular [de Lovecraft] mezcla de horror y ciencia ficción, su visión única que enfatiza al cosmos en lugar del hombre, y su construcción cuidadosa de la atmósfera como virtual protagonista (traducción propia)] (p. 33).

Por consiguiente, la construcción adecuada de la atmósfera, la predisposición del estado anímico, el énfasis en el cosmos y el miedo a lo desconocido y los personajes patéticos son algunos de los elementos constitutivos de la poética de Lovecraft, bautizada como Weird Fiction o ficción de lo extraño.

En el artículo "Monstruos. Acercamiento a una pequeña teoría de las formas de la imaginación política" (2012), Jordi Claramonte Arrufat indica que un monstruo es una configuración de relaciones cuya susceptibilidad compromete la cohesión interna del ser humano. Por cohesión interna, el autor se refiere al equilibrio entre las acciones y sentimientos que definen al hombre y que por consiguiente le permiten subsistir en el mundo y poseer una identidad bien definida:

Nuestra cohesión interna, es decir, el equilibrio entre acciones y pasiones que nos define, nos permite mantenernos vivos y ser lo que somos sin entrar en dinámicas de renuncia servil o vergonzante acomodación a lo establecido. Perder esa cohesión característica, venderla por un plato de lentejas o un monovolumen con aire acondicionado, es lo más parecido a morir, si es que no es peor. Aunque se suele dar por sentado que la mayoría de los monstruos pretenden matarnos, esa no es más que una de las variantes de la fatal pérdida o disgregación de nuestra cohesión interna. Al final resultará que hay muchas muertes posibles, tantas como formas de dilapidar la inteligencia y perder la dignidad (p. 4).

Por ello, perder esta cohesión interna, venderla, desperdiciarla o prostituirla equivale a una muerte en vida. Una vez que Claramonte define su concepto del monstruo, procede a tratar el tema de algo por demás interesante para la investigación: el estilo del monstruo. 
Al decir que todo monstruo que sea considerado como tal tiene las firmes intenciones de destruir la cohesión interna del individuo (o víctima), pero lo hace de una manera propia y característica. En pocas palabras, el denominado monstruo no atenta de cualquier modo porque tiene un estilo propio definido. El estilo constituye al monstruo. Pero dicho estilo debe ser entendido como una modulación concreta cuya función es amenazar, atenazar y disminuir la capacidad de hacer y comprender de la víctima. El giro teórico en los supuestos de Claramonte estriba en que existen monstruos que pueden comprometer la cohesión social, por lo que se prescinde de la figura del monstruo reducida a un esperpento sobrenatural para encarnar a la aristocracia, la política y las creencias populares (p. 4).

Cabe añadir lo siguiente: es de suponerse que la figura monstruosa, ya desgastada, requiera adoptar nuevos matices para sobrevivir. Entonces, la figura del monstruo como entidad física, antropomorfa o etérea debe sostener su capacidad de transgredir el orden natural del mundo. Siempre que se dé la transgresión podremos hablar de literatura fantástica, y en los casos pertinentes, de Weird Fiction.

\section{Análisis de "El amor no tiene cura".}

Incluido en el libro de cuentos Los niños de paja (2014), "El amor no tiene cura" narra la historia de un hombre que acaba de divorciarse y que acude a una pitonisa para que le ayude a recuperar a su amada. Al salir de su apartamento, el hombre se topa con una rata que yace muerta ante la puerta de uno de sus vecinos, misma que elude con recelo. Posteriormente, la pitonisa le confirma que es posible recuperar el amor perdido, y le encarga regresar en tres días con un ramo de crisantemos, no sin advertirle que algo le va a impedir acudir a la consulta. A partir de este momento, el protagonista adoptará medidas drásticas para sortear las trampas del destino que, según él, le impedirían regresar con la pitonisa. Tales medidas implican dejar de bañarse y de preparar alimentos ante la falta de gas, eludir interacciones sociales, conducir despacio y evadir a la rata muerta, misma que nadie se digna a remover. En el transcurso de la semana tiene un sueño recurrente en el que la pitonisa lo visita en su cuarto y le repite la frase: "yo vivo en los débiles y en 
los heridos" (p. 56), además de vejarlo sexualmente. Cuando acude a la segunda cita, descubre que la pitonisa no recuerda las indicaciones que le dio, por lo que se siente desconcertado. Al regresar a su hogar, descubre una segunda rata, viva, junto a la muerta. Después de matarla en un arranque de cólera, entra a su apartamento y se dice a sí mismo: "Pon atención a cualquier ruido. Vendrán más ratas. Ellas no se largarán jamás" (p. 62). El conflicto principal del protagonista (el deseo de recuperar a su esposa) no llega a ninguna resolución.

\subsection{Superstición en "El amor no tiene cura".}

Como se ha podido intuir, una de las líneas temáticas principales del relato es la superstición. El comportamiento del protagonista y los sucesos narrados dan cuenta inequívoca de ello; son el hilo conductor del cuento.

Ciertamente, la superstición se manifiesta como una respuesta ante la angustia o una manera de enfrentarse a las desavenencias de la vida. Siguiendo a Susana Arroyo (2006), un individuo supersticioso es aquel de pensamientos contrarios al raciocinio y cuyas acciones se encaminan a no padecer las consecuencias de un acontecimiento (p. 4). En el cuento de Esquinca (2014), el proceder del personaje principal se ve guiado por la angustia de su situación actual, es decir, el malestar producido por el abandono de su esposa. Una vez advertido por la pitonisa, el eje rector de sus acciones cambia: la creencia en el vaticinio sobre algo que le impedirá regresar a su segunda consulta le orilla a adoptar medidas drásticas para evitar una mala pasada del destino.

Como se mencionó anteriormente, dichas medidas comprenden dejar de bañarse y de preparar alimentos (ya que, al llegar a su casa, descubre que se ha quedado sin gas) para evitar una posible enfermedad; declinar una invitación de su vecina (ya que podría distraerle de su objetivo) y manejar con antelación y precaución excesivas a su segunda cita con la pitonisa (para evitar retrasos o accidentes y sortear posibles imprevistos). Este comportamiento puede catalogarse como supersticioso, siguiendo la teoría propuesta por Susana Arroyo, pues el personaje adopta estas prevenciones por el temor a las consecuencias del vaticinio. 
Además, el impulso del personaje está sustentado en la necesidad de recuperar a su esposa mediante rituales supersticiosos. Iñaki Bazán (1998) alude, definiendo a la magia, a un pacto con fuerzas sobrenaturales cuyo objetivo es satisfacer deseos y pasiones humanas (p. 107). Es importante destacar que los sucesos del texto en cuestión coinciden con lo planteado, pues el personaje de Esquinca desea satisfacer su deseo de recuperar el amor perdido sirviéndose de la intervención de la pitonisa. Para reforzar lo mencionado, es preciso rescatar las propuestas de Enrique Enríquez (2010), quien define a "La superstición como pivote entre el miedo y la esperanza ofrece modelos del mundo que podemos controlar aunque no podamos controlar al mundo" ( $p$. 20).

En "El amor no tiene cura", es precisamente la superstición el punto de equilibrio entre el miedo y la esperanza del personaje. Esto es notorio desde el primer diálogo entre el protagonista y la pitonisa: "-Perdiste una mujer - dijo. - Sí, mi esposa me dejó hace seis meses. -Todavía la amas. Ella a ti también. La puedes recuperar... - ¿Cómo? Haré lo que sea" (Esquinca, 2014, p. 54), lo que posteriormente lo conduce a cambiar su comportamiento para conseguir el dominio de una situación incontrolable. La superstición provoca una reacción en el individuo, por lo que la adapta a su cotidianidad y le dota de un propósito específico que sirve para resanar las eventualidades de la vida.

Es esta adaptación de la superstición a su quehacer cotidiano lo que propicia, por otro lado, la inserción de símbolos en la narración. Miguel Roiz (2002) acuña una característica importante de la superstición, pues la relaciona con "una tendencia colectiva a atribuir un carácter sobrenatural, sagrado y oculto, a determinados hechos relacionados con la naturaleza de la tierra [...] o bien precedentes de la acción humana" (p. 37). Esta tendencia es una constante en el proceder del personaje, que no duda en atribuir sucesos determinados a las trampas del destino y la predicción de la pitonisa, quien, por otro lado, dota de significado esotérico a ciertas acciones insignificantes. Algunos ejemplos de ello:

La Pitonisa [...] salió del cuarto de lectura y, al verme con las piernas cruzadas, me reprendió: - Nada de brazos ni piernas cruzadas, si no no llego a ustedes - después tomó una veladora 
de un anaquel y regresó, cerrando la puerta tras de sí [...]. La Pitonisa me ordenó quitarme los lentes. -Para mirarte mejor-, dijo con una absurda voz de niña que no encajaba con su voluminoso cuerpo [...]. Ya adentro, descubrí otro asunto desagradable: se había acabado el gas. Era lunes y los de la compañía pasarían a surtir hasta el viernes, por lo que tendría que bañarme con agua fría todos esos días. "Ni madres", pensé, “¿y si me enfermo?” Había detectado la primera trampa del destino para impedirme llegar a mi cita con la Pitonisa [...]. Me invitaron a tomar una cerveza en un bar cercano, pero me negué pretextando cansancio: esos muslos de granito eran sin duda otra trampa para desviarme de mi objetivo (Esquinca, 2014, pp. 53, 54, 55, 56).

Esta inclinación de los personajes a atribuir características supersticiosas a los hechos del mundo se manifiesta a través de la configuración de hierofanías. En palabras de Mircea Eliade (2012), las hierofanías son la evidencia de algo sagrado que se revela (p. 15). Así, en "El amor no tiene cura" el personaje principal y la pitonisa actúan como hierofantes, dado a que atribuyen características sobrenaturales, sagradas y/u ocultas a los hechos del mundo. Sin embargo, es necesario destacar que el protagonista funge como hierofante principal, puesto que los significados que construye le obligan a reconfigurar las condiciones de su contexto: es por ello que deja de bañarse, cocinar y salir a divertirse.

Al mismo tiempo, las cualidades que atribuye a sus sueños y la vejación que lo aqueja en ellos, así como la rata muerta, se sustentan en la hierofanía. Ello se debe a la explicación que el personaje ofrece sobre sus sueños, al preguntarse si la pitonisa de verdad lo visita como súcubo o a través de viajes astrales.

El caso de la rata es también de interés, pues es un elemento narrativo constante desde el inicio hasta el final. Cuando el protagonista la ve por primera vez, hace una descripción que, si bien no está completamente influenciada por la pitonisa (ya que aún no acude con ella), sí puede tomarse como la manifestación de algo siniestro:

Salí de mi departamento aquella mañana y, frente a la puerta de uno de mis vecinos, encontré una rata muerta. Enorme. Parecía un gato. Más que repugnancia, sentí miedo: 
aquello era un mensaje concreto sobre lo que se gesta en los intestinos de la ciudad (Esquinca, 2014, p. 53).

Posteriormente, la visión de la rata es una constante en el tiempo narrativo, ya que el personaje continúa viéndola al salir y llegar a su apartamento, siempre negándose a retirarla.

Pero es al final cuando el personaje deposita una carga simbólica en el animal. A su regreso de la segunda consulta con la pitonisa, se decide por fin a deshacerse del cadáver. Pero al entrar, descubre a la segunda rata, viva, junto a la muerta. En una ráfaga de furia, mata a la segunda rata: “Exhausto y salpicado de sangre y vísceras diminutas, regresé a mi departamento. Me senté en el sillón de la sala, escoba en mano. Me dije: ‘Pon atención a cualquier ruido. Vendrán más ratas. Ellas no se largarán jamás'” (p. 62). Esta frase, que marca el final de la narración, denota la consideración que el personaje establece con las ratas; las toma como una condena constante a la que se verá sometido, imposibilitado de superar su malestar. De este modo, las ratas quedan reconfiguradas a partir de una hierofanía que, en este caso, permanece oculta de su forma final hasta que el relato termina.

Las ratas, una vez reconfiguradas, suponen un peso adicional al relato. La amenaza inherente de ciertos elementos narrativos surge desde lo interior, develando los peligros ocultos en el punto más álgido de tensión. La afirmación final del protagonista alude a ello con base en la hierofanía y el pensamiento supersticioso. Al mismo tiempo, la preocupación del personaje por que las ratas continúen apareciendo denota un estado de desesperación y patetismo, recursos propios del género Weird Fiction que se analizarán más adelante.

Para finalizar, es necesario tomar en cuenta la creencia absoluta del personaje en los procesos y predicciones de la pitonisa, cuestión que está implícita en el relato y que es otra manifestación de la superstición en el mismo. 


\subsection{Weird Fiction en "El amor no tiene cura".}

Rescatando el postulado de José Pulido (2004) en "El horror: un motivo literario en el cuento latinoamericano y del Caribe", se menciona que "Al inducir terror, los primeros hombres avisaron que estaba próximo lo descomunal (lo no conocido), el propio horror se hace presente sin encontrar explicación lógica" (pp. 231-232). En el relato de Esquinca (2014), es notable la manera en que el protagonista se induce terror al no poder explicar la procedencia de sus sueños con la pitonisa y por lo tanto padece el miedo a repetir la experiencia. Así lo expresa:

Un pensamiento me mantuvo distraído todo el tiempo: ¿y si ella en verdad me estaba visitando en sueños, en una especie de viaje astral? Y lo peor de todo: ¿había ella abusado de mí, como súcubo que buscaba alimentarse con mi esperma? Esa noche, la anterior a la cita, tuve insomnio. Estaba aterrado. Cerrar los ojos podía significar caer en las carnes abundantes de la Pitonisa (p. 57).

Desde el vaticinio de la pitonisa, el personaje siente la inquietud de no saber cuál será el obstáculo que supuestamente le impediría regresar a la segunda cita: "Todo el día estuve inquieto y no me pude concentrar. Una duda fue creciendo en mí: ¿a qué se refería la Pitonisa con aquello de que algo me iba a impedir llegar a la cita?" (p. 55). El impedimento de dar una respuesta lógica a estos sucesos inocula miedo en el personaje.

Ligando lo anterior con las propuestas de Lovecraft en Supernatural horror in literatura (2014), es notorio el miedo a lo desconocido, mismo que para Lovecraft es el miedo más antiguo y poderoso (párr. 1) en el personaje de Esquinca. Los ejemplos ofrecidos con anterioridad denotan ese miedo que produce la incertidumbre de su contexto.

Por otro lado, y enfocándose en el receptor, Lovecraft (2014) destaca la importancia de la atmósfera y su manejo, ya que la narración debe despertar emociones en el lector mediante sus elementos sobrenaturales. Parte de esta atmósfera contiene la ansiedad o el temor ante lo ignoto y la presencia de fuerzas desconocidas que enfrenten a las leyes naturales del mundo. Es por ello que Lovecraft sostiene que la ficción de lo extraño debe juzgarse no por la intención autoral, sino por el 
nivel emocional que logre evocar (párr. 7). En el relato de Esquinca, las descripciones de la rata muerta y los sueños tergiversan la atmósfera de lo cotidiano y la reconfiguran, contribuyendo a establecer la atmósfera Weird por sus características de origen ignoto y sobrenatural, respectivamente:

Salí de mi departamento aquella mañana y, frente a la puerta de uno de mis vecinos, encontré una rata muerta. Enorme. Parecía un gato. Más que repugnancia, sentí miedo: aquello era un mensaje concreto sobre lo que se gesta en los intestinos de la ciudad [...]. Giré en la cama y entonces la vi: la Pitonisa estaba en un rincón del cuarto, observándome. Me quedé helado [...]. Volví a soñar con la Pitonisa. Esta vez me miraba desde el techo. Y estaba desnuda. Sus carnes colgaban como estalactitas de grasa [...]. Su lengua entró en mi boca y en ese momento pasó algo extraño: empezó a frotarme la laringe con la punta, como si de pronto se le hubiera transformado en una serpiente. [...] Parecía como si la Pitonisa se hubiera enfundado en el cuerpo de mi esposa como quien se pone un disfraz. Y el olor tampoco era el de Mariana: olía a agua estancada, a pantano (pp. 53, 56, 57, 58).

Sumando lo anterior al grado mínimo de imaginación que, según Lovecraft, el lector debe poseer para que el género Weird Fiction surta efecto, no es difícil evocar sensaciones de asco, miedo y otras cualidades de lo grotesco. Los espacios cotidianos (el dormitorio, el pasillo) se ven transgredidos por estos elementos, por lo que es lógico sentir incomodidad al imaginar dichos espacios invadidos.

Otra característica de Weird Fiction estriba en el patetismo de los personajes. Como apunta Saijamari Männikkö, si los humanos de la narrativa de Lovecraft fueran héroes, sus relatos no serían Weird ni horripilantes (2002, p. 10). Ya que sus personajes se ven impedidos de comprender los horrores cósmicos y los misterios del universo, se contribuye a instaurar la incertidumbre. Además, Männikkö (2002) supone que la concepción filosófica de Lovecraft sobre la total insignificancia de la humanidad es uno de los factores más importantes en la creación de Weird Fiction. Trasladando el ejemplo a la narrativa de Esquinca, existen varios pasajes textuales que evidencian el patetismo del protagonista: 
Lo peor de todo es que sí me había orinado. Carajo, eso no me pasaba desde la secundaria. Fui un mojacamas veterano, qué le voy a hacer. Me marché al trabajo. Así, meado y sin bañarme [...]. Los compañeros me veían raro: mi aspecto debía ser terrible, sin bañarme ni rasurarme. Me valía madres: cumpliría la misión de ir con la Pitonisa, pasara lo que pasara [...]. El espejo me devolvió el rostro de un vagabundo [...]. Pero como mi malestar no pasó ni los consejos del I Ching ayudaron mucho, acabé aquella mañana en mi auto frente al local de la Pitonisa, con unas ojeras profundas y un olor acre en el cuerpo. iLas cosas absurdas que un hombre abandonado es capaz de hacer con tal de recuperar a su mujer! (2014, pp. 56-60).

En ello se refleja el estado penoso, lamentable y ridículo en el que se halla el personaje, reduciéndose a una figura deplorable. En la segunda consulta con la pitonisa, se revela otro momento de patetismo:

Yo estaba intrigado con el asunto de sus visitas nocturnas a mi cuarto, así que le tiré un anzuelo: -Yo vivo en los débiles y en los heridos. —¿ ¿Perdón? - dijo, extrañada. Como podía estar fingiendo, contraataqué: -Te gusta ir a verme a mi cuarto, ¿no es cierto? Me miró como quien mira a un loco y continuó con su perorata (p. 61).

Otro ejemplo notable ocurre al final del cuento, cuando el protagonista se siente a merced de las ratas que continuarán llegando y que no se largarán jamás, pues, concluidas sus visitas a la pitonisa y los estragos en su persona, continúa sumiéndose en un estado deplorable al sentirse abatido por la presencia de los roedores. De este modo se confirma que el patetismo es una de las constantes en el personaje de "El amor no tiene cura".

Kézia L'engle (2003), por su parte, menciona que Weird Fiction enfatiza al cosmos y a lo desconocido como protagonistas virtuales de la narración (p. 33). En el cuento de Esquinca (2014), la figura del protagonista es prominente, no hay duda de que su personaje es fundamental para la trama. Sin embargo, es preciso recalcar que la atmósfera de lo desconocido (en los sueños) supone un pilar indispensable de la narración. Cuando inicia la vejación de la pitonisa hacia el protagonista, 
el énfasis narrativo cambia, se vuelca en el miedo del personaje a dormir y "caer en las carnes abundantes de la Pitonisa" (p. 57).

Dentro del análisis de los elementos de Weird Fiction en el cuento, es preciso abordar la figura antagónica. En el caso tratado, se podría depositar la carga antagónica en la entidad monstruosa de la pitonisa que sueña el protagonista, ya que compromete la cohesión interna del personaje. De acuerdo a la teoría de Jordi Claramonte (2012), un monstruo es una configuración de relaciones que compromete la cohesión interna del hombre. Por cohesión interna, el autor comprende el equilibrio entre las acciones y sentimientos que definen al hombre. En la misma línea de ideas, el teórico menciona que existen varias muertes posibles, como mermar la inteligencia y perder la dignidad (p. 4). La vejación que el personaje de Esquinca sufre en sus sueños, pero que se presenta en el plano real (al amanecer orinado o eyaculado) lo humilla, compromete su cohesión interna y contribuye a su estado patético al hacerle perder la dignidad.

Además, Jordi Claramonte (2012) hace énfasis en el estilo del monstruo, mismo que define como "una específica modulación empeñada en amenazar, atenazar y disminuir nuestra potencia de obrar y comprender" (p. 4), y tal es el caso de la pitonisa soñada por el protagonista, pues lo reduce a un estado de miedo e incertidumbre que lo angustia en su día a día: “¿y si ella en verdad me estaba visitando en sueños, en una especie de viaje astral? [...] ¿había ella abusado de mí, como súcubo que buscaba alimentarse con mi esperma?" (Esquinca, 2014, p. 57). Este hecho se relaciona con la sugestión generada por el horror, que a su vez, puede enlazarse con el grado de imaginación del receptor. En "El amor no tiene cura", la sugestión juega un doble papel: primero, el de comprometer la imaginación del lector y segundo, en invadir la psique del protagonista. Es de este modo como se corrompe su cohesión interna para llevarlo al estado de incertidumbre y patetismo, a través del estilo del monstruo que se erige en la pitonisa.

En síntesis, "El amor no tiene cura" contiene elementos propios de Weird Fiction, concretamente el miedo a lo desconocido, la presencia de supuestas fuerzas sobrenaturales, la transgresión de la atmósfera cotidiana, la apelación a la imaginación del lector, el patetismo del personaje principal, el énfasis en lo desconocido como protagonista virtual, la configuración del 
monstruo y su estilo y la sugestión. Resulta interesante destacar que dichos elementos no aparecen de manera forzada en el cuento; más bien resultan como sucesos encadenados que propician el avance de la trama. Este hecho funge como indicador de la vigencia de Weird Fiction en la literatura actual.

\section{Conclusiones.}

La construcción narrativa de lo extraño moderno en el cuento "El amor no tiene cura" de Bernardo Esquinca, se nutre de los elementos de superstición y Weird Fiction que impulsan la trama: ambas forman las partes constitutivas del cuento. El propósito de este trabajo fue evidenciar la confluencia del concepto de superstición aunado a la identificación de las partes constitutivas de la ficción de lo extraño.

Los componentes supersticiosos en el cuento seleccionado enriquecen la trama, a su vez, se rescata un concepto valioso para los estudios humanísticos, pues al tratarse de comportamientos propios del hombre (llegando a extremos irracionales), se alude no sólo a su empleo literario, sino también a sus aportes culturales. Extraer estos rasgos y espacios de la superstición, evidencia la multiplicidad de voces culturales que convergen en una sociedad donde son suprimidas ante la hegemonía.

La teoría sobre Weird Fiction demostró su propia vigencia, y esta se torna todavía más valiosa al poder aterrizarla en una muestra literaria mexicana. Weird Fiction añade un toque especial a la narrativa de Bernardo Esquinca, pues al apegarse a los preceptos del maestro Lovecraft, el autor escapa del lugar común del realismo mágico y las reglas canónicas de lo extraño para instaurar un sistema en el que impera el tratamiento atmosférico, la fragilidad humana y los misterios del universo, además de hacer partícipe al lector con la predisposición anímica y su competencia imaginativa, entre otros elementos ominosos.

La vigencia, funcionamiento y viabilidad de la superstición como línea temática literaria, así como Weird Fiction y su funcionamiento, son elementos activos en el cuento analizado, cuyo grado de importancia les condiciona a no poder desligarse del corpus textual. 


\section{Referencias}

Arroyo, R. S. (2006). "Magia y superstición en la era de Internet”. En Revista Culturas Populares, (2), 143.

Bazán, D. I. (1998). “El mundo de las supersticiones y el paso de la hechicería a la brujomanía en EuskalHerria (Siglos XIII al XVI)". En Revista Vasconia, (25), 103-133.

Claramonte, A. J. (2012). “Monstruos. Acercamiento a una pequeña teoría de las formas de la imaginación política". En Revista Araucaria, 14(27), 3-23.

Eliade, M. (2012). Lo sagrado y lo profano. España: Paidós.

Enríquez, E. (2010). “Las supersticiones como modelo para entender el poder de la ficción”. En Revista Cuadernos Unimetanos, (23), 19-22.

Esquinca, B. (2014). Los niños de paja. México: Almadía.

L'engle, K. (2003). Weird Fiction and the unholy glee of H. P. Lovecraft (tesis de maestría). Universidad Federal de Santa Catarina, Brasil. Recuperado de https://repositorio.ufsc.br/xmlui/bitstream/handle/123456789/86573/193275.pdf?sequence=1 \&isAllowed $=\mathrm{y}$

Lovecraft, H. P. (2014). Supernatural horror in literature [Versión electrónica]. Australia: The University of Adelaide Library. Recuperado de https://ebooks.adelaide.edu. au/l/lovecraft/hp/supernatural ¿index.html.

Männikkö, S. (2002). H. P. Lovecraft and the creation of horror (tesis de posgrado). University of Tampere, Finlandia. Recuperado de http://tampub.uta.fi/bitstream/handle/10024/89419/gradu00093.pdf

Pulido, J. A. (2004). "El horror: un motivo literario en el cuento latinoamericano y del Caribe". En Revista Contexto, 8(10), 229-250.

Roiz, C. M. (2002). “Nuevas supersticiones de masa, medios de comunicación e ideología del conformismo". En Revista Barataria, (5), 36-50. 